\title{
Information pathways into prison mental health care
}

Authors: Chiara Samele ${ }^{1,2}$, Norman Urquía ${ }^{1,2}$, Karen Slade ${ }^{3}$ and Andrew Forrester ${ }^{1,4}$

\section{Authors' affiliations:}

Chiara Samele

(Forensic \& Neurodevelopment Science), Institute of Psychiatry, Psychology and Neuroscience, King's College London, UK; Informed Thinking Ltd, UK

Norman Urquía

(Forensic \& Neurodevelopment Science) Institute of Psychiatry, Psychology and Neuroscience, King's College London, UK; Informed Thinking Ltd, UK

Karen Slade

(Division of Psychology), Nottingham Trent University, UK

Andrew Forrester

(Forensic \& Neurodevelopment Science), Institute of Psychiatry, Psychology and Neuroscience, King's College London, UK; South London and Maudsley NHS Foundation Trust, UK

${ }^{1}$ Institute of Psychiatry, Psychology and Neuroscience, King's College London, London, UK

2 Informed Thinking Ltd, London, UK

${ }^{3}$ Nottingham Trent University, Nottingham, UK

${ }^{4}$ South London \& Maudsley NHS Foundation Trust, London, UK

Corresponding author: 
Chiara Samele: Informed Thinking, 10 Grove Road, London SW19 1BL, UK.

Email: Chiara.samele@kcl.ac.uk

\section{Abstract}

Police and court liaison and diversion services provide important specialist mental health input along critical stages of the criminal justice pathway. Effective sharing of information between the services and relevant justice agencies is essential. However, various problems exist with the flow of information between agencies and services across the criminal justice pathway. This service evaluation explored how clinically relevant information is transferred, by drawing on the perspectives of prison healthcare staff in a large urban UK male prison. A qualitative service evaluation was conducted using semi-structured interviews with a purposive sample of 11 prison staff. The main themes included: gaps in the transfer of essential information, (particularly concerning risk and offending information); information gathering to fill these gaps; the importance of professional relationships, information sharing between 
agencies; and information solutions. Improving information transfer across the criminal justice pathway could prevent treatment delays and ensure more timely mental healthcare in prison.

\section{Keywords}

Prisoners; information flow; prison mental healthcare; qualitative method; men

\section{Introduction}

The mental health of prisoners with serious mental health problems is an important priority; given the 2-4 fold increase in psychotic disorders compared to the general population (Fazel \& Seewald, 2012; Fazel \& Danesh, 2002. Dressing \& Salize, (2009) emphasized the need to provide adequate mental healthcare for this group, including health reporting and assessment. 


\section{Prison mental health services}

Responsibility for prison mental healthcare In England and Wales lies with the National Health Service (NHS), in 2004 inreach teams were introduced as the main vehicle for improving mental health care for prisoners (Steel et al., 2007). Inreach teams are broadly based on community mental health teams (CMHT), comprising a specialist multidisciplinary team with a limited caseload size. Prison mental health services may also include an inpatient unit and a primary mental health care to treat less serious mental illness.

\section{Liaison and diversion mental health services}

In 2009, the Bradley review called for better support for people with mental health problems or learning difficulties throughout the criminal justice (CJ) system in England and Wales (Bradley, 2009). The report recommended the expansion of liaison and diversion (L\&D) services in police stations and courts to enable timely clinical reporting to the 
court, better transfer of information, improved identification of mental health problems across the pathway and signposting to relevant services.

A recent systematic review found that $L \& D$ services did effectively identify offenders with mental health problems, improve psychosocial outcomes, for example substance use, quality of life, symptomatology and reduce days in prison/recidivism (Scott et al., 2013).

In 2014, NHS England developed a standardised operational model of L\&D services; in which emphasised effective information sharing between L\&D services and 'relevant justice agencies'. The central idea was that decision makers would be able to make more "informed decisions on diversion, charging, case management, reasonable adjustments and sentencing" (NHS England, 2014).

The current model for information flow is that at each stage in the criminal justice system defendants / prisoners who display mental health symptoms will routinely receive an assessment and for this 
information to be recorded and presented at reception when they are admitted into a new criminal justice agency.

Information gathering and transfer should continue at various points of the criminal justice pathway. In police custody, defendants are routinely screened for mental health concerns (Noga et al, 2014), any issues found are recorded and a hard copy should follow individuals through their F2050 file if they enter prison.

In court, court L\&D services usually contact relevant services if mental health issues are identified and if the individual is sentenced or remanded to custody, a prison escort record (PER) will accompany them as they are transferred between all stages of the CJS. This mandatory document should record risk, safety and health concerns and contacts with professionals, such as solicitors and health professionals. (Prison Service Order 1025, Ministry of Justice, 2009). Offending history and index offence are recorded on the prison's database system, PrisonNomis (P-Nomis). SystmOne, is a database used by prison healthcare 
staff to record all patients' medical notes, which is shared between prisons.

\section{Barriers to effective mental health care for offenders}

L\&D services were developed in England and Wales with the intention of diverting people into the most appropriate care and some recent evidence suggests these services do help inform decisions about whether to remand an individual to custody from court (Disley et al., 2016). One issue, which may interrupt or halt prisoners' mental health care are difficulties with information flow between different parts of the CJ / health pathway. This is partly due to incompatible information systems, differing service demands and difficulty obtaining hospital beds at the point of need (Roberts et al., 2012; Royal College of Psychiatrists, 2011). In addition, once offenders are received into prison custody, their mental health information may not be effectively transferred from the police and/or the court to prison reception. 
There are established protocols for collecting data within services and transfer of minimum data sets between agencies, but little if any published literature describes how the system works in practice and how information on mental health issues is transferred between the police and the court and prison reception and prison mental health services.

The aim of this service evaluation therefore was to explore the availability, collection and transfer of information between these agencies by drawing on the first-hand experience prison mental health staff.

\section{Method}

This service evaluation employed a qualitative approach to allow participants to describe their experiences of the information gathering and transfer process to address the main service evaluation aim. 


\section{Setting}

The service evaluation was located in a large urban male prison with approximately 1,600 prisoners $-44 \%$ on remand and $37.3 \%$ foreign nationals (HM Chief Inspector of Prisons, 2015). The prison served several city courts and healthcare was provided by two local NHS Foundation Trusts.

\section{Sampling participants}

The service evaluation used a purposive sample (Marshall,1996) to identify mental healthcare staff and prison officers who carried out different roles and would therefore have experience of different aspects of information flow across different points on the patient journey.

A list of current mental healthcare staff in the prison was made which included prison officers in the mental health inpatient unit, general healthcare staff and reception nurse. Staff were emailed a summary of the service evaluation aims and invited to take part in an anonymous 
interview. The interviews were carried out in a private setting in the prison. All the staff who were emailed consented to be interviewed and for recordings or anonymised notes to be used in the service evaluation.

\section{Interviews}

Semi structured interviews lasted between 30 to 60 minutes and were conducted by a researcher, $\mathrm{CS}$, in a private area of the prison between December 2015 to March 2016.

A semi-structured interview schedule was developed to explore, which information is obtained, required and collected by prison healthcare staff at different points in prisoners' journeys. Staff described the process for generating, receiving and passing on information to and from other agencies on the CJ pathway. This included the contact staff had with the police, courts and specifically Liaison and Diversion 
services (L\&D); the information obtained from reception and the information needed and collected once a person is referred and taken on by the prison mental health inreach service.

Interviews were recorded digitally where consent was given and prison security permitted the use of this equipment. On one occasion hand written notes were made during the interview and typed up by the interviewer shortly afterwards.

\section{Data analysis}

A thematic analysis was carried out on the transcripts (Braun \& Clarke, 2006); and guided by the aims of this service evaluation which were used to develop predefined themes: information gaps, types of information collected and information collection processes. Two raters (CS and NU) coded the texts according the themes and patterns identified in the data. NVivo Version 10 (2014) (qualitative analysis software package) was used to code, retrieve and analyse data. Once an initial list of themes had been generated the texts were recoded and 
sorted by theme and each was retrieved and reread to identify the patterns in the texts. Themes were checked for appropriateness and alternative interpretation through subsequent iterations of coding and recoding.

\section{Study approval}

Service evaluation approval was granted by the South London and Maudsley NHS Foundation Trust's Research Outcomes and Service

Evaluation (ROSE) Committee in July 2015; approval number 151.

\section{Results}

Eleven interviews were completed, ten with healthcare staff and one with a senior prisoner officer. Table 1 lists the job titles of professionals interviewed.

[Table 1 about here] 
Four main themes were identified in the transcripts, which highlight the information that prison mental health staff encounter; information gaps, (especially risk and offending), information gathered to fill these gaps and verify information; the importance of relationships and information sharing between agencies; and information transfer solutions (see Figure 1).

[Figure 1 about here]

Figure 2 illustrates the information pathways into prison, the information collected and the gaps.

[Figure 2 about here]

\section{Information gaps}

According to the model, prison officers at reception automatically receive mental health information about new prisoners in the Prisoner Escort Records (PER) (Prison Service Orders, 2009) (see Figure 1). The 
PERs should include information about risk, health, safety and contact with professionals at the police station/court.

However in practice staff were sometimes unclear about what health information actually travelled with newly arrived prisoners in the PER whch they expected to contain CJ records rather than mental health information.

'I don't know what sort of information [PER] is meant to bring. I wouldn't expect them to have any medical information. I would expect them to have, whatever prison records if somebody has a prison record ... but (not)... any access to any medical information.' (Inreach nurse 1)

This indicates that staff can be unaware of the requirements of the PER but also that they would not expect mental health records to be included.

Prison mental health staff also indicated that they did not automatically receive mental health information for prisoners at this point even if 
mental health issues had been identified by police/court L\&D services.

Communication between the prison and police mental health team also seems to be limited

Information from the police station is practically zero and the inreach team don't seem to have much communication with them.

Occasionally [we] get the odd phone call from the police but there are information sharing issues re risk. (Inreach nurse2)

Even though the mental health information may not be included within the PER, there were sometimes concerns about also legal restrictions on contacting the police which could further impede the transfer of information for individual prisoners.

"We seldom receive info from the police. [We] can look at CNOMIS for info if there is a risk issue, staff cannot talk to police for legal reasons etc." (Inreach nurse)

On occasions, the mental health information might be available to the prison if the defendant had been assessed in court. 
'We rarely get given that information. ... Sometimes if they've [the prisoner] had an assessment at the court [nurse X] might have access to that (Consultant Forensic Psychiatrist 1)

However, Primary Care Mental Health nurse (PCMH) also explained that Mental health information is usually not passed through from the courts via prison reception for their purposes. This indicates that the communication between police and court liaison is not being relayed to the prison.

Risk and offending information

As well as a lack of mental health information, information about a new prisoner's index offence, offending history or risk is also not immediately available to prison mental health staff and this was also seen as a crucial omission.

'to be managing risk we should have access to their offending history ... definitely their index offence. It's not to say that we can't access that but it's not always immediately available... nursing 
staff can access (P-Nomis) to get their index offence...[But] it doesn't give you their history of offending. We can request that but you're not then allowed to put that on SystmOne ${ }^{1}$ '(Consultant Forensic Psychiatrist 1)

Therefore the situation appeared to be that prisoners offending history and mental health records were being recorded separately which is a major concern when managing risk among a potentially vulnerable group.

Information on a prisoner's health and offending history is important for clinical and judicial decision-making, particularly in relation to hospital orders, fitness to plead and care/treatment. This information was later collected by the mental health team administrator from the Crown Prosecution Service and Police National Computer for all those taken on by the prison mental health service. Mental health staff

${ }^{1}$ SystmOne is the prison's database for healthcare professionals. 
reported that offending history and index offence can sometimes be requested directly from the court or the police, but more usually they have to pursue information from other services shortly after imprisonment.

\section{Information gathering}

In this prison reception, a general nurse conducts an initial standardised health screen on all new prisoners (Grubin et al., 1999). If the person reports having mental health problems and/or that they are in contact with mental health services the nurse will refer the person directly to the prison mental health service.

If concerns are raised about a prisoner's mental health by the nurse at reception or a prison officer from the main wing then a referral is sent to the PCMH team; usually the first port of call into the mental health service. Information in these referrals is often sparse, reflecting the limited time available for assessment during the reception process: 
'A nurse from reception [might say in their referral] 'odd behaviour, please see' or it could be 'is on antidepressants please review'. Or ... the prison officers have said 'this guy's a bit odd can you see them'. Or ... we know that this guy has been in hospital before, has a history of mental health problems, 'can you see them'. It's very rarely much more information than that.' (Consultant Forensic Psychiatrist 1)

Gathering information begins immediately after referral as so little is known about the person at this stage. If reception mentions the person has been assessed by the court L\&D service the PCMH nurse will seek details about any assessments, contact with mental health services and current medication. SystemOne is checked initially as it may hold some relevant information if the prisoner has been seen previously by another prison mental health service.

Essential information for prison mental health staff includes previous/current contact with mental health services, past admission to psychiatric hospital (especially recent ones), medication, index offence 
and risk. If a person is referred by the court $L \& D$ service, this information will be provided directly to the prison mental health service via fax. A typical scenario, was for mental health staff to have to investigating the patients background and filling in the gaps in their profile.:

'Yesterday, I triaged somebody. The only information I had was from the first night screen through the GP (General Practitioner) [in prison] saying 'this man has got mental health problems, he's under a mental health team, he's on depot medication, please go and review'. I didn't know which [CMHT] team he was under because that question didn't get asked in first night reception. I have to go and see the patient before I can gather any information. I try to look on P-Nomis, not updated so no information. So I tried to gather as much information as I could from the patient...' (Inreach nurse 1)

\section{Information from prisoners}


Information collected directly from the prisoner has to be verified through external health services, particularly any medication they report to be taking. Before any information gathering can commence mental health staff need prisoner's written consent to access health information from their GP or CMHT. An over-riding issue for the prison mental health inpatient unit is that their prisoners are often unable to provide basic information for several weeks:

'Our medical teams have to treat and support [prisoners] on what they see. In some cases it might be a couple of weeks later when the person is more coherent and willing to engage with staff [and] we're able to get clearer bits of information. At those times we try to seek the patient's consent to get information from their GP... and explain why we want this information.' (Team Leader, Prison psychiatric inpatient unit)

Prisoners may also have incomplete recollection of their mental health history, they may not know their GP and may choose to withhold information about their mental health condition and treatment. Staff 
indicated that this presented an increased risk for safety, for example suicide or self-harm particularly on the first night where staff may not be aware of mental health issues that had not been disclosed.

For foreign nationals, prison mental health staff initially rely on the information from the prisoner, mostly through interpreters. Many are not registered with a GP and foreign consulates are often an only source of very limited information.

\section{Relationships and information sharing}

Professional relationships between the prison mental health staff and the court/police L\&D, GPs and CMHTs are well established and essential given the gaps in automated information provision, but confidentiality laws govern information sharing between services. As a result information gathering from services outside the prison can be time consuming:

'... we have to persist with it as best as we can. Further and collateral information is always useful...' (PCMH nurse) 
There are also good informal relationships between doctors and the Crown Courts, which provide the best information received by the prison inreach services. This is because of the requirements for expert witness reports. The information 'bundle' received by forensic psychiatrists contains high quality, comprehensive information including details of the alleged offence, police records, witness statements and GP records. However, this is often received three to four months after the person has entered prison:

'... it's great to receive that information and that interface works very well, but it is quite late in the day for patient care.' (Consultant Forensic Psychiatrist 2)

Relationships between the prison officers and mental health staff were particularly good. On the psychiatric inpatient unit prison officers provided important feedback at weekly ward rounds and considered themselves as 'healthcare enablers'. 
'On every single ward round you've got the doctor's perspective, the nurses' perspective and the officers' perspective. Everyone's perspective is slightly different but together you can actually get a balanced view.' (Senior Prison Officer)

The importance of close working relationships between $\mathrm{CJ}$ and health professionals was emphasised in the Bradley Review (Bradley, 2009), although it acknowledged the complexities of these to support offenders with mental health issues or learning disabilities. The move to develop a standardised model for L\&D services is important, but alongside this more effective methods for communicating essential information to prison mental health services needs to established. Informal knowledge between staff across agencies would back up routine formal information sharing, allowing individuals to be tagged for further investigation without breaching confidentiality arrangements. 


\section{Discussion}

A key finding of the service evaluation is that relevant mental health information is not being -automatically transferred to prison mental health staff for new prisoners with mental health issues. This presents an important information gap for prison mental health staff, especially as the earliest stages of imprisonment are known to be the highest point of systemic risk, particularly for suicide (Felthous, 2011).

A separate evaluation found that some information was transferred from the police or court to the prison service, but was not included onto SystmOne for healthcare to see (Slade et al., 2016). Only when a person is identified as having mental health problems does the process of information gathering appear to commence. This is concerning for two reasons; there is possible duplication of effort in screening / assessment which may take place in the police station, court and at prison reception. 
Secondly, the lack of information results in teams relying on prisoners disclosing their history of mental health problems, which may be inaccurate or patchy (particularly if unwell) risking the onward mental health care they require.

The availability of a L\&D team at police stations and courts has enabled police and Judges to make more informed decisions (Durcan et al., 2014). However, the lack of information transfer to prison mental health services may be due to court $L \& D$ teams not having timely access to information about a person's disposal (e.g. whether L\&D teams know if a person has been remanded/sentenced to custody until it is too late). If this information was fedback to court L\&D teams rapidly prison mental health staff could be alerted sooner. This situation is further compounded by competitive tendering across $\mathrm{CJ}$ healthcare pathways where multiple providers creates interface problems across the whole system (Forrester et al., 2015). 
Previous studies have shown how offenders with mental health problems in the $\mathrm{CJ}$ system are missed and better screening tools have been adopted to reduce this oversight (McKinnon et al., 2013; Senior et al., 2013; Shaw et al., 2008). Slade et al. (2016) in their evaluation of the same prison found only $3 \%$ prisoners were identified with serious mental illness on reception but 33\% displayed acute symptoms later in their imprisonment.

Inconsistencies in transferring mental health information to health files may have led to those at risk being missed. Prison receptions are often very busy and it is unsurprising that people slip through the safety net. Although this should be avoided and can be where a second comprehensive screening process is available (Jarrett et al., 2012) and was in the service evaluation prison. The introduction of a mental health nurse in one prison reception can also ensure a more detailed process for identifying mental health issues (Samele et al., 2016; Brown et al., 2015). 
The gap in information often delayed the identification and treatment of prisoners with mental health problems. So improving communication and the transfer of information along the $\mathrm{CJ}$ pathway can ensure better continuity and access to care (Byng et al., 2012); and minimise risk.

\section{Information transfer solutions}

Participants' suggestions in relation to overcoming information transfer difficulties included automatic alerts to update shared records when prisoners enter prison:

'the minute somebody comes under our care there's an automatic trigger that these documents are requested and then they're put on SystmOne so that it doesn't have to be done every time they come under our care.' (Consultant Forensic Psychiatrist 1)

Another proposed solution was for individual staff to work across agencies so they would be aware of individuals moving between services. 
...teams in each place and ... some individuals working across the [CJS] pathways. So you might have joint team leadership... Consultants working in different parts of the pathways, ... CPNs (Community Psychiatric Nurses) working in both in the prison and in the court or working in both the court and in the police station.' (Consultant Forensic Psychiatrist 2)

Other suggested improvements include the introduction of more coherent pathways and better interfaces of care (Gilbert et al, 2014).

A unitary system across $\mathrm{CJ}$ agencies (police stations, courts and prisons) could resolve many information transfer issues. So, commissioning CJ Mental health services across the entire pathway, rather than in spot locations, could help staff work across different $\mathrm{CJ}$ locations and promote better information transfer. The NHS England are currently considering bringing SystmOne into police stations and courts which could alert prison mental health staff to any new prisoners assessed by police or court L\&D teams, a recommendation also made by Slade et al. (2016). 


\section{Strengths and limitations}

The perspectives of the prison staff within one urban prison is not representative of other prisons or other regions. Interviews with $L \& D$ professionals would have helped understand how they share information with the other agencies.

\section{Conclusions}

The perceived lack of essential information routinely transferred to prison reception and prison mental health staff is concerning. Automatic transfer of information recently collected at police stations or courts could prevent delays in care and treatment in prison. Improved information flows could prevent prisoners being missed at reception who later become acutely unwell later in their imprisonment. Continuity of care is paramount for this population; hence it is important to ensure that information is transferred efficiently between 
CJ agencies without compromising confidentiality. A unitary system of services and shared access to relevant databases across the pathway could help achieve this.

Further research is needed to examine how information travels between

$\mathrm{CJ}$ agencies and the most efficient and effective ways to achieve this.

\section{Acknowledgements}

We thank NHS England who provided funding to support this service evaluation, to clinical and prison staff who participated.

Funders: This work was supported by the NHS England.

\section{Disclosure statement}

No potential conflict of interest was reported by the authors. 


\section{References}

Braun, V., \& Clarke V. (2006). Using thematic analysis in psychology. Qualitative Research \& Psychology, 3, 77-101.

Bradley, K. (2009). The Bradley Report. Lord Bradley's review of people with a mental health problem or learning disabilities in the criminal justice system. London: Department of Health.

Dressing, H., \& Salize, H-J. (2009). Pathways to psychiatric care in European prison systems. Behavioural Science \& the Law, 27, 801-10.

Brown, K., Cullen, A., Kooyman, I., \&Forrester, A. (2015).Mental health expertise at prison reception. Journal of Forensic Psychiatry \& Psychology, 26, 107-15.

Byng, R., Quinn, C., Sheaff, R., Samele, C., Duggan, S., Harrison, D.,Owens, C., Smithson, P., Wright, C., Annison, J., Brown, C., Taylor, R., Henley, W., Qureshi, A., Shenton, D., Porter, I., 
Warrington, C., \& Campbell J. (2012). COCOA: Care of Offenders Continuity of Access. NIHR Service Delivery and Organisation programme. Retrieved from http://www.netscc.ac.uk/hsdr/files/project/SDO FR 08-1713210 V01.pdf

Disley, E., Taylor, C., Kruithof, K., Winpenny, E., Liddle, M., Sutherland, A., Lilford, R., Wright, S., McAteer, L., \& Francis, V. (2016) Evaluation of the Offender Liaison and Diversion Trial Schemes. Cambridge: RAND Europe. Retrieved from: http://www.rand.org/content/dam/rand/pubs/research reports/R R1200/RR1283/RAND RR1283.pdf

Durcan, G., Saunders, A., Gadsby, B., \& Hazard, A. (2014). The Bradley Report five Years on. An independent review of the progress to date and priorities for further development. London: Centre for Mental Health. Retrieved from http://www.centreformentalhealth.org.uk/the-bradleyreport-five-years-onFazel, S., \& Seewald, K. (2012). Severe mental illness in 33588 prisoners 
worldwide: systematic review and meta-regression analysis. British Journal of Psychiatry, 200, 364-73.

Fazel, S., \& Danesh, J. (2002). Serious mental disorder in 23000 prisoners: a systematic review of 62 surveys. The Lancet, 359, $545-50$.

Felthous, A.R. (2011) Suicide behind bars: trends, inconsistencies, and practical implications. Journal of Forensic Sciences, 56, 1541-55.

Forrester, A., Till, A., Senior, J., \& Shaw, J. (2015). Competitive tendering and offender health services. Lancet Psychiatry, 2, 859-61.

Gilbert, H., Edwards, N., \& Murray, R. (2014). Transforming mental health. A plan of action for London. London: Kings Fund. Retrieved from: http://www.kingsfund.org.uk/sites/files/kf/field/field_publication_file/tra nsforming-mental-health-london-kingsfund-sep2014.pdf Grubin, D., Parsons, S., \& Hopkins, C. (1999). Report on the evaluation of A New reception health questionnaire and associated training. 
Report for Her Majesty's Prison Service.

HM Chief Inspector of Prisons. (2015). Report on an unannounced inspection of HMP Wandsworth by HM Chief Inspectors of Prisons. 23 February - 6 March 2015. London: Her Majesty's Inspectorate of Prisons. Retrieved from https://www.justiceinspectorates.gov.uk/hmiprisons/wpcontent/uploads/sites/4/2015/07/Wandsworth-web-2015.pdf Jarrett, M., Craig, T., Parrott, J., Forrester, A., Winton-Brown, T., Maguire, H.,McGuire, P., \& Valmaggia, L. (2012). Identifying men at ultra high risk of psychosis in a prison population. Schizophrenia Research, 136, 1-6.

Marshall, M.N. (1996). Sampling for Qualitative Research. Family Practice, $13,522-526$.

McKinnon, I., \& Grubin, D. (2013). Health screening of people in police custody - evaluation of current police screening procedures in London, UK. European Journal of Public Health, 23, 
399-405. NHS England. (2014). Operating Model for Liaison and Diversion 2013/2014.

2014. Retrieved from https://www.england.nhs.uk/wpcontent/uploads/2014/04/ld-op-mod-1314.pdf

Noga, H., Walsh, E., Shaw, J., \& Senior, J. (2015). The development of a mental health screening tool and referral pathway for police custody. The European Journal of Public Health, 25(2), 237-242.

Prison Service Orders (PSOs). (2009). The person escort record. Retrieved From: https://www.justice.gov.uk/offenders/psos

Roberts, A., Senior, J., Hayes, A., Stevenson, C. \& Shaw, J. (2012). An independent evaluation of the Department of Health's procedure for the transfer of prisoners to hospital under the Mental Health Act 1983. Journal of Forensic Psychiatry \& Psychology, 23, 217-36. 
Royal College of Psychiatrists (2011) OP81 Prison transfers: A survey from the Royal College of Psychiatrists. London: Royal College of Psychiatry.

Samele, C., Forrester, A., Urquía, N., \& Hopkin, G. (2016). Key successes and challenges in providing mental health care in an urban male remand prison: a qualitative study. Social Psychiatry \& Psychiatric Epidemiology, 51, 589-96.

Scott, D.A., McGilloway, S., Dempster, M., Browne, F., \& Donnelly, M. (2013). Effectiveness of criminal justice liaison and diversion services for offenders with mental disorders: A review. Psychiatric Services, 64, 843-49.

Senior, J., Birmingham, L., Harty, M.A., Hassan, L., Hayes, A.J., Kendall, K., King, C., Lathlean, J., Lowthian, C., Mills, A., Webb, R., Thornicroft, 
G., \& Shaw, J. (2013). Identification and management of prisoners with severe psychiatric illness by specialist mental health services. Psychological Medicine, 43, 1511-20.

Shaw, J., Senior, J., Hassan, L., King, D., Mwasambilli, N., Lennox, C., Sanderson, M., \& Weston, J. (2008). An evaluation of the reception screening process used within prisons in England and Wales. Manchester: Offender Health Research Network. Retrieved from http://www.ohrn.nhs.uk/OHRNResearch/RecepScreen.pdf

Slade, K., Samele, C., Valmaggia, L. \& Forrester, A. (2016) Pathways through the criminal justice system for prisoners with acute and serious mental illness. Journal of Forensic and Legal Medicine, 44, 162-168.

Steel, J., Thornicroft, G., Birmingham , L., Brooker, C., Mills, A., Harty, M., 
\& Shaw, J. (2007) Prison mental health inreach services. British Journal of Psychiatry, 190, 373-74. 